\title{
Audit and Feedback-Focused approach to Evidence-based Care in Treating patients with pneumonia in hospital (AFFECT Study)
}

\author{
Katelyn Halpape, Linda Sulz, Brenda Schuster, and Ron Taylor
}

\begin{abstract}
Background: Pneumonia is the eighth leading cause of death in Canada. Use of guideline-concordant therapy tempers the development of resistance, decreases health care costs, and reduces morbidity and mortality.

Objectives: The purpose of this study was to optimize the treatment of patients with pneumonia under hospitalist care by focusing on best practice and local antibiogram data. The objectives were to collaborate with a hospitalist representative to optimize in-hospital treatment of patients with community-acquired, hospital-acquired, and health care-associated pneumonia; to complete a baseline audit to determine the proportion of antibiotic orders adhering to the strategy; to present the strategy and baseline audit findings to the hospitalists; to perform a post-intervention audit, with comparison to baseline, and to present results to the hospitalists; to expedite de-escalation to a narrowerspectrum antibiotic; to expedite parenteral-to-oral step-down therapy and promote appropriate duration of therapy; and to determine if a pneumonia scoring system was used.
\end{abstract}

Methods: An audit and feedback intervention focusing on pre- and post-intervention retrospective chart audits was completed. Review of pneumonia guidelines and the local antibiogram assisted in identifying the study strategy. A presentation to the hospitalists outlined antimicrobial stewardship principles and described the findings of the baseline audit. Pre- and post-intervention audit results were compared.

Results: Local best-practice treatment algorithms were developed for community-acquired pneumonia and for hospital-acquired and health care-associated pneumonia. The pre-intervention audit covered the period December 2011 to January 2012, with subsequent education and audit results presented to the hospitalists in November 2012. The postintervention audit covered the period December 2012 to January 2013. Adherence to the treatment algorithms increased from $10 \%(2 / 21)$ in the pre-intervention audit to $38 \%(5 / 13)$ in the post-intervention audit. There was a trend to reduced duration of therapy in the postintervention group.

Conclusion: An audit and feedback intervention related to hospitalists' prescribing for pneumonia increased adherence to local best practice.

Keywords: pneumonia, antimicrobial stewardship, audit and feedback

\section{RÉSUMÉ}

Contexte : La pneumonie est la huitième cause de mortalité au Canada. L'utilisation d'un traitement qui respecte les lignes directrices permet de freiner le développement de la résistance, de diminuer les coûts de soins de santé et de réduire la morbidité et la mortalité.

Objectifs : Le but de cette étude était d'optimiser le traitement des patients atteints de pneumonie qui sont suivis par des médecins hospitaliers en mettant l'accent sur les meilleures pratiques et les données locales d'antibiogrammes. Les objectifs étaient de collaborer avec un représentant des médecins hospitaliers afin d'optimiser les traitements à l'hôpital de patients atteints d'une pneumonie extrahospitalière, nosocomiale ou associée aux soins de santé; d'effectuer une vérification initiale afin d'établir la proportion d'ordonnances d'antibiotiques qui respectent la stratégie; de présenter la stratégie et les conclusions de la vérification initiale aux médecins hospitaliers; d'effectuer une vérification post-intervention ainsi qu'une comparaison de cette dernière à la vérification initiale et de présenter les résultats aux médecins hospitaliers; d'accélérer le passage à un antibiotique à spectre plus étroit; de hâter le passage d'un traitement parentéral à un traitement oral et de favoriser le respect de la durée recommandée de la thérapie; et de déterminer si un système de notation pour la pneumonie a été utilisé.

Méthodes : Une vérification et une intervention de rétroaction portant sur les vérifications rétrospectives de dossiers médicaux pré- et postintervention ont été réalisées. Un examen des lignes directrices de traitement de la pneumonie et des données locales d'antibiogrammes a aidé à définir la stratégie d'étude. Une présentation destinée aux médecins hospitaliers exposait les principes de gestion responsable des antimicrobiens et décrivait les conclusions de la vérification initiale. Les résultats des vérifications pré- et post-intervention ont été comparés.

Résultats : Des algorithmes de traitement stipulant les meilleures pratiques locales ont été élaborés pour la pneumonie extra-hospitalière et pour les pneumonies nosocomiale et associée aux soins de santé. La vérification pré-intervention a porté sur la période de décembre 2011 à janvier 2012 et elle a été suivie de la présentation des conclusions en découlant aux médecins hospitaliers ainsi que de la formation de ceuxci en novembre 2012. La vérification post-intervention a porté sur la période de décembre 2012 à janvier 2013. L'observance des algorithmes de traitement est passée de $10 \%(2 / 21)$ lors de la vérification pré-intervention à $38 \%(5 / 13)$ lors de la vérification postintervention. Une tendance à la réduction de la durée du traitement dans le groupe post-intervention a été observée. 
Can J Hosp Pharm. 2014;67(1):17-27
Conclusion : Une vérification et une intervention de rétroaction portant sur les habitudes de prescription des médecins hospitaliers traitant les personnes atteintes de pneumonie ont permis d'améliorer l'observance des meilleures pratiques locales.

Mots clés : pneumonie, gestion responsable des antimicrobiens, vérification et rétroaction

\section{INTRODUCTION}

$\mathrm{P}$ neumonia is the eighth leading cause of death in Canada. ${ }^{1}$ The incidence of pneumonia and death related to pneumonia has continued to escalate despite advances in health care and antimicrobial therapy. ${ }^{2-5}$ The development of pneumonia in a hospital inpatient is associated with an estimated excess cost of about US\$4947 per patient and extends the hospital stay by approximately 8 days., ${ }^{3,5}$ Appropriate and timely antibiotic treatment of pneumonia reduces the risk of complications, helps curb the development of antibiotic resistance, decreases health care costs, and reduces morbidity and mortality. ${ }^{6-10}$

Inappropriate empiric antibiotic therapy is associated with an increased risk of death, prolonged length of hospital stay, higher rates of clinical failure, and more frequent readmission to hospital. ${ }^{11-14}$ Changing therapy once culture results are available may not reduce this risk; therefore, appropriate empiric therapy is essential for an optimal outcome..$^{8,11-14}$

\section{Classification of Pneumonia}

Pneumonia is classified based on the setting where it is acquired: hospital-acquired pneumonia (HAP), health care-associated pneumonia (HCAP), and community-acquired pneumonia (CAP)..$^{2-4}$

HAP, an inflammatory condition of the lungs that develops more than $48 \mathrm{~h}$ after hospital admission, is caused by infectious agents that were not present or incubating at the time of admission. ${ }^{4}$ Late-onset HAP occurs $96 \mathrm{~h}$ after admission and commonly involves multidrug-resistant (MDR) pathogens. ${ }^{3,4}$

HCAP is diagnosed in patients with one or more of the following characteristics: hospitalized in an acute care institution for more than 1 day in the previous 3 months, received IV antibiotic therapy or chemotherapy, received wound care in the past 30 days, attended a hospital or hemodialysis clinic, or residence in a nursing home or long-term care facility. ${ }^{4}$ The pathogens associated with HCAP vary depending on the specific type of facility and patient population. ${ }^{15}$

CAP is an acute infection of the lungs in a patient who does meet any of the HCAP criteria and who was not hospitalized at the time of symptom onset. ${ }^{16}$ Determining the site of initial treatment is an important clinical decision in managing patients with CAP and is often based on severity. ${ }^{2,16}$ Prognostic models such as the Pneumonia Severity Index (PSI) or the CURB-65 severity score (based on confusion, uremia, respiratory rate, blood pressure, and age) can be used as a guide, in conjunction with clinical judgment, to identify patients who are at low risk for adverse outcomes and who may be treated in an outpatient setting., ${ }^{2,16-19}$ The PSI is time-consuming to use, as it requires the calculation of a score based on 20 variables; in contrast, the CURB-65 score is easier to use and relies on calculation of only 5 variables. ${ }^{18,19}$

\section{Treatment of Pneumonia}

A variety of pneumonia treatment guidelines have been published. . $-4,20-24$ Differences between these guidelines complicate prescribing and may result in non-guideline-based treatment. ${ }^{2}$ To provide effective treatment for a specific clinical setting, local microbiologic data should be used in conjunction with published evidence-based guidelines, as resistance patterns can vary markedly. ${ }^{2,3}$

\section{Antimicrobial Stewardship and Audit and Feedback Programs}

Antimicrobial stewardship refers to the appropriate selection, dosing, route, and duration of antimicrobial therapy. ${ }^{25}$ Resistance to antimicrobial agents is increasing, and the development of novel antimicrobial agents is lacking, which places increased importance on antimicrobial stewardship. ${ }^{26}$ Two core strategies providing the foundation for an antimicrobial stewardship program are prospective audit of antimicrobial use (with intervention and feedback to the prescribing physician) and formulary restriction. ${ }^{25}$ The first of these core strategies formed the basis of the AFFECT study, reported here. Persuasive and restrictive interventions have been shown to be equally effective after 6 months. ${ }^{27}$

Audit and feedback constitute an approach that is used to improve practice, involving measurement of an individual's or group's practice and comparison with standards or targets. ${ }^{28}$ The feedback component includes dissemination of the results in relation to a standard, with the belief that health care 
professionals are compelled to adjust their practice when their performance is inconsistent with the group or desired target. ${ }^{28,29}$ Audit and feedback generally lead to small but potentially important improvements in professional practice. ${ }^{5.28}$

Barriers to the implementation of antimicrobial stewardship include the need to obtain adequate administrative support and potential antagonism from prescribers..$^{30,31}$ Including prescribers in the development of a program before implementation can effectively overcome these barriers. ${ }^{32}$

A previous audit and feedback pilot study of antimicrobial stewardship in the critical care setting demonstrated that a formal, prospective audit and feedback program led to more appropriate use of broad-spectrum antimicrobial agents and illustrated that pharmacists can play a pivotal role in promoting appropriate antimicrobial utilization..$^{32,33}$

Goal 3, objective 3.9 of the Canadian Society of Hospital Pharmacy 2015 initiative- “...pharmacists will be actively involved in medication- and vaccination-related infection control programs"-further supports the proposition that pharmacists should actively apply evidence-based methods to the improvement of antimicrobial treatment. ${ }^{34}$

\section{Prescriber Practice}

Individual prescribing practices may differ depending on professional practice area or training. Hospitalists are distinct from other physicians in that they practise medicine full-time within an institutional setting. ${ }^{35}$ Increasing evidence supports hospitalists' ability to better manage hospital resources, shorten average length of stay, reduce health care expenditures, and potentially improve patient outcomes. ${ }^{35,36}$ As stated by Rosenberg of the North Shore University Hospital in Long Island, New York, "hospitalists are positioned as excellent champions of the principles and practices of antimicrobial stewardship". ${ }^{37}$

Hospitalists at the authors' institution expressed interest in partnering with hospital pharmacists to evaluate their antimicrobial prescribing practice. This set the stage for an antimicrobial stewardship study to effect practice change.

\section{Purpose and Objectives}

The overall purpose of this study was to optimize the antibiotic treatment of pneumonia for patients under hospitalist care according to antimicrobial stewardship principles focusing on best practice and local antibiogram data.

The specific objectives were to collaborate with a hospitalist representative to optimize in-hospital treatment of patients with HAP, HCAP, or CAP; to complete a baseline audit to determine the proportion of antibiotic orders adhering to the strategy; to present the strategy and baseline audit findings to the hospitalists; to perform a post-intervention audit, with comparison to baseline, and to present results to the hospitalists; to expedite de-escalation to a narrower-spectrum antibiotic; to expedite parenteral-to-oral step-down therapy and promote appropriate duration of therapy; and to determine if a pneumonia scoring system was used.

\section{METHODS}

The study consisted of 3 phases: a baseline chart audit, an educational intervention, and a post-intervention chart audit. The study methods were developed in collaboration with a hospitalist representative (R.T.). Eight local hospitalists served the study population in both the pre- and post- intervention phases. The study was approved by the Regina Qu'Appelle Health Region Research Ethics Board.

\section{Identifying Best Practice}

The initial steps to devise the study strategy included a review of the literature and collaboration with the hospitalist representative. These steps were followed by review of the health region's current antibiogram and consultation with the local infectious disease specialists and medical microbiologist.

\section{Study Population and Timelines}

Patients at least 13 years of age admitted to hospital with pneumonia were identified for inclusion in the study. The pre-intervention audit covered the period from December 1, 2011, to January 31, 2012, and the post-intervention audit from December 1, 2012, to January 31, 2013. The audit periods were limited to 2 months each, because of time constraints on the primary investigator (K.H.) to complete the project during a 1-year hospital pharmacy practice residency. Patients with active tuberculosis and patients undergoing mechanical ventilation were excluded, as the treatment options did not apply to these groups.

\section{Pre-Intervention Chart Audit}

A retrospective chart audit, covering the period December 1, 2011, to January 31, 2012, was performed to identify the antibiotics prescribed by local hospitalists. Data collection was completed using Fluid Surveys (http://fluidsurveys.com), a Canadian software system for online survey and data collection.

Patient characteristics were collected for comparison between groups. Outpatient medication profiles were reviewed to identify antibiotic use during the 3 months before hospital admission. Data to calculate both the PSI and CURB-65 scores were collected for group comparison purposes. Adherence to best practice was evaluated using the study strategy described above (Figure 1). 


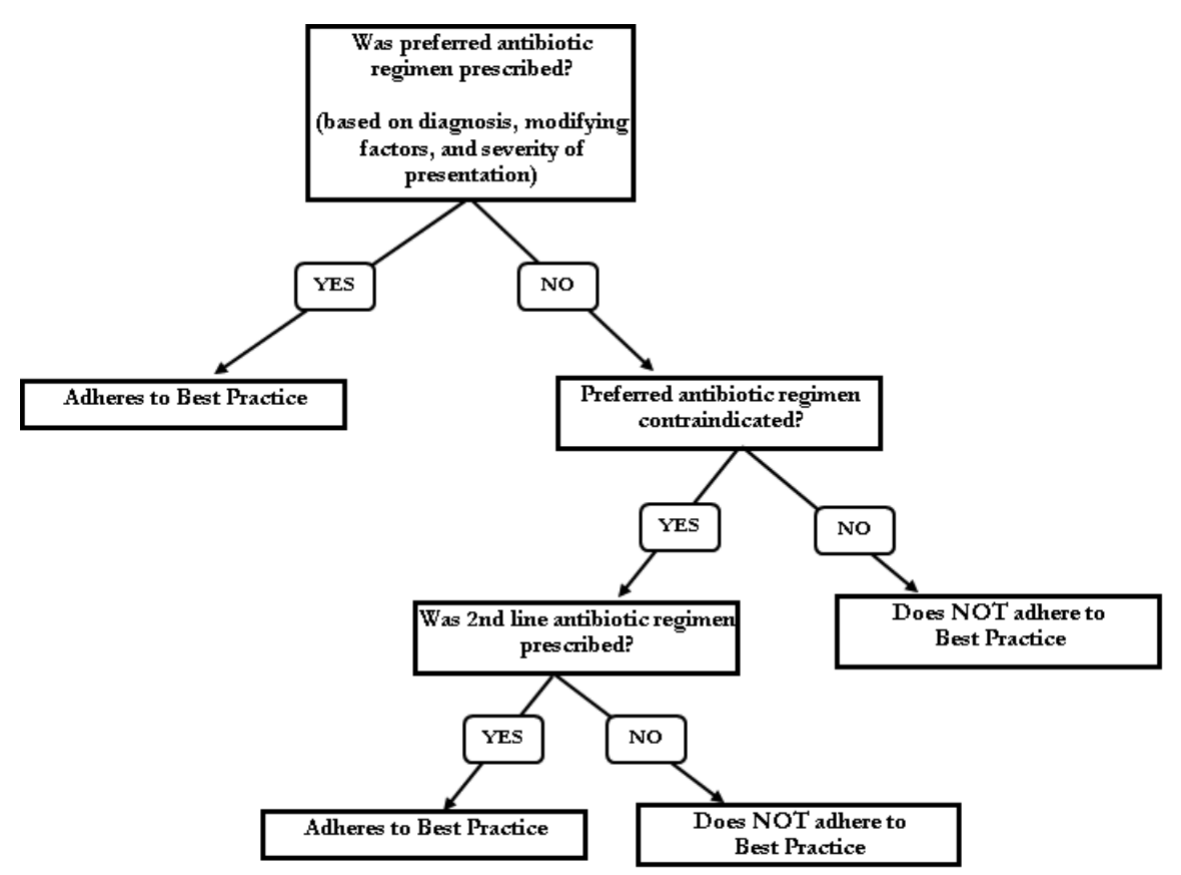

Figure 1. Study strategy for the AFFECT study (Audit and Feedback-Focused approach to Evidence-based Care in Treating patients with pneumonia in hospital). This strategy was used to determine whether each hospitalist adhered with best practice for antimicrobial prescribing for patients with pneumonia.

Table 1. Patient Characteristics

\begin{tabular}{|c|c|c|c|}
\hline \multirow[b]{2}{*}{ Characteristic } & \multicolumn{2}{|c|}{ No. $(\%)$ of Patients* } & \multirow[b]{2}{*}{$p$ Value } \\
\hline & $\begin{array}{l}\text { Pre-intervention } \\
\quad(n=21)\end{array}$ & $\begin{array}{l}\text { Post-intervention } \\
\quad(n=13)\end{array}$ & \\
\hline Sex, male & $12(57)$ & $5(38)$ & 0.29 \\
\hline Age (years) (median and IQR) & $81(51.5-88.5)$ & $80(54.5-88)$ & 0.88 \\
\hline Antibiotic allergy & $2(10)$ & $3(23)$ & 0.27 \\
\hline Antibiotics in previous 3 months & $13(62)$ & $6(46)$ & 0.37 \\
\hline \multicolumn{4}{|l|}{ Type of pneumonia } \\
\hline Health care-associated & $14(67)$ & $6(46)$ & 0.24 \\
\hline Hospital-acquired & $4(19)$ & $2(15)$ & 0.78 \\
\hline Community-acquired & $3(14)$ & $5(38)$ & 0.28 \\
\hline \multicolumn{4}{|l|}{$\begin{array}{l}\text { Risk factors for multidrug- } \\
\text { resistant pathogenst }\end{array}$} \\
\hline $\begin{array}{l}\text { Antimicrobial therapy in previous } \\
3 \text { months }\end{array}$ & $13(62)$ & $5(38)$ & 0.37 \\
\hline Current hospital stay $\geq 5$ days & $3(14)$ & $2(15)$ & 0.53 \\
\hline $\begin{array}{l}\text { Immunosuppressive disease } \\
\text { or therapy }\end{array}$ & $1 \quad(5)$ & 1 (8) & 0.72 \\
\hline Total & $17(81)$ & $8(62)$ & 0.21 \\
\hline
\end{tabular}

$\mathrm{IQR}$ = interquartile range.

*Except where indicated otherwise.

†Associated with health care-associated, hospital-acquired, or community-acquired pneumonia. 


\section{Educational Intervention and Audit and Feedback}

Literature searches with the subject headings "guideline adherence", "physician's practice patterns", "professional education", "audit and feedback", "antimicrobial stewardship", and "drug utilization" were conducted to identify previously successful strategies promoting antimicrobial stewardship and practice change. An educational strategy utilizing audit and feedback was then developed.

The primary investigator was invited to present at the monthly hospitalist meeting on November 29, 2012. The presentation focused on antimicrobial stewardship principles, identified best practice, and individual and group findings of the baseline audit.

\section{Post-intervention Audit}

The post-intervention chart audit was conducted in the same manner as the pre-intervention audit. $\chi^{2}$ analysis was used to determine if there had been any improvement in adherence to best practice. The final study results were presented to the hospitalists on May 30, 2013.

\section{RESULTS}

\section{Population}

There were no significant differences between the pre- and post-intervention patient groups (Table 1). In the pre-intervention audit, the institution's Health Information Management Services identified 24 potentially eligible patient visits, of which 3 were excluded, leaving a total of 21 for study analysis (Figure 2 ). In the post-intervention audit, 21 patient visits were identified for review, of which 8 were excluded, leaving a total of 13 (Figure 3).

\section{Development of Best Practice}

A comprehensive literature search of the MEDLINE, International Pharmaceutical Abstracts, and Embase databases with subject headings "pneumonia", "anti-bacterial agents", and "practice guidelines" was completed to identify best practice for the treatment of HAP, HCAP, and CAP. The most recent local antibiogram (for 2010/2011) defining susceptibility of respiratory isolates was used to tailor antibiotic choices. Two treatment algorithms, one for CAP and one for HAP and HCAP, were then developed in collaboration with the hospitalist representative. Local infectious diseases specialists and a medical microbiologist, as well as infectious diseases pharmacists from other Canadian centres, were consulted to assist with the selection of antibiotic treatments to appear in the algorithms. The local infectious diseases and medical microbiology specialists made suggestions for changes, and final deliberation was completed in consulta- tion with the hospitalist representative and local infectious diseases pharmacist. (The algorithms are available in Appendices 1 and 2, online at www.cjhp-online.ca/index.php/cjhp/issue/ view/100/show Toc).

Creation of the pneumonia treatment algorithms was challenging, as the guideline recommendations are wideranging and varied. ${ }^{2-4,21-24}$ It is also not well defined whether HCAP treatment should align with CAP or HAP therapy. ${ }^{38-46}$

The classification of HCAP was introduced in the 2005 American Thoracic Society/Infectious Diseases Society of America (ATS/IDSA) guidelines, ${ }^{3}$ which suggested that patients who develop pneumonia in the community and have specific risk factors should be treated similarly to those with HAP, including coverage for MDR pathogens (Table 2). The frequency of MDR pathogens and whether all MDR risk factors are relevant in all practice settings is unclear and complicate determination of antibiotic recommendations using local data. ${ }^{38-46}$

Given limited identification of MDR pathogens in the authors' health region and to prevent the unnecessary use of broad-spectrum antibiotics, the algorithms did not incorporate all MDR risk factors identified by the ATS/IDSA guidelines (Table 2). The most common MDR pathogens identified in the health region were Pseudomonas aeruginosa and methicillin-resistant Staphylococcus aureus (MRSA) (Table 3). Very few MDR Enterobacteriaceae species and Acinetobacter species have been identified in the health region.

It was felt that resistance patterns in this health region aligned more closely with those in Britain than those in the United States, which allowed for reduced use of broadspectrum antibiotics. ${ }^{47,48} P$. aeruginosa is the most common MDR gram-negative pathogen causing HAP in the United States, with a prevalence of $14 \%-16 \%$ and resistance rates as high as $19 \%$ for ceftazidime, $14 \%$ for piperacillin-tazobactam, $18 \%$ for meropenem, $35 \%$ for ciprofloxacin, and 16\% for tobramycin. ${ }^{3,49}$ In contrast, the 2010/2011 local antibiogram identified the prevalence of $P$. aeruginosa in respiratory isolates as $8.7 \%$ and the resistance rates as $8 \%$ for ceftazidime, $5 \%$ for meropenem, $11 \%$ for ciprofloxacin, and $1 \%$ for tobramycin; i.e., considerably more susceptible (Table 3). Therefore, empiric $P$. aeruginosa coverage was recommended for a more defined patient population than in the ATS/IDSA guidelines, and carbapenems were not listed.

Another area of controversy in developing the treatment algorithms related to the use of a second-generation cephalosporin (e.g., cefuroxime). ${ }^{2-4,21,23,24}$ Oral amoxicillinclavulanate was recommended over oral cefuroxime because of its better oral bioavailability and lower cost. ${ }^{50,51}$ IV ceftriaxone, a third-generation cephalosporin, was preferred over IV cefuroxime on the basis of its increased coverage of Streptococcus pneumoniae, as well as broader coverage of gram-negative 
organisms. ${ }^{50,51}$ The local antibiogram for respiratory isolates reported that S. pneumoniae susceptibility was $81 \%$ for cefuroxime and $92 \%$ for ceftriaxone; therefore, amoxicillinclavulanate and ceftriaxone were chosen for the algorithms. The hospitalists expressed concern regarding gastrointestinal intolerance with amoxicillin-clavulanate but stated there had been no reports of patient gastrointestinal discomfort. Tobramycin was selected as the aminoglycoside of choice, as local susceptibility data showed $P$. aeruginosa isolates were $99 \%$ susceptible to this drug (only 90\% susceptible to gentamicin), and there were no other limiting factors for use (e.g., tolerability, cost).

A variety of recommendations for empiric coverage of MRSA appear in the literature. ${ }^{2-4,21-24}$ Given the low frequency of MRSA respiratory isolates in the health region (6.3\%), empiric MRSA coverage was recommended only for patients with a previous positive culture or confirmed colonization with MRSA. During the post-intervention meeting, the hospitalists indicated that they often consider IV drug users to be at risk for MRSA. This is consistent with findings that IV drug users have a higher rate of nasal or skin colonization with $S$. aureus than the general population and that nasal carriage is associated with an increased risk of subsequent infection. The rate of MRSA colonization in IV drug users has been reported as about $19 \% .5253$

The algorithms emphasized avoidance of any antibiotic from the same class as used in the previous 3 months, as this may contribute to the development of antibiotic resistance. ${ }^{54,55}$

\section{Educational Intervention}

On November 29, 2012, at the monthly hospitalists' meeting, the primary investigator presented an overview of the study and provided instructions on using the treatment algorithms, to ensure accurate interpretation. Feedback was solicited to modify the algorithms, if warranted. There were only minor suggestions for change, which were subsequently incorporated. This process did not require re-examination of the pre-intervention audit results.

A pivotal point in the meeting was dissemination of the pre-intervention audit findings. Each hospitalist was given a sealed envelope containing his or her data on pre-intervention prescribing practices and a personal identifier to allow for anonymous comparison with the other hospitalists' practice, as well as comparison with the group's collective practice.

The hospitalists were encouraged to carry copies of the treatment algorithms with them, and posters were placed on the nursing units most commonly frequented by the hospitalists. Brief educational in-services about the study were provided to the nurses on these units and to the health region pharmacists, to increase their awareness of the study and its implications for potential change in antibiotic prescribing.
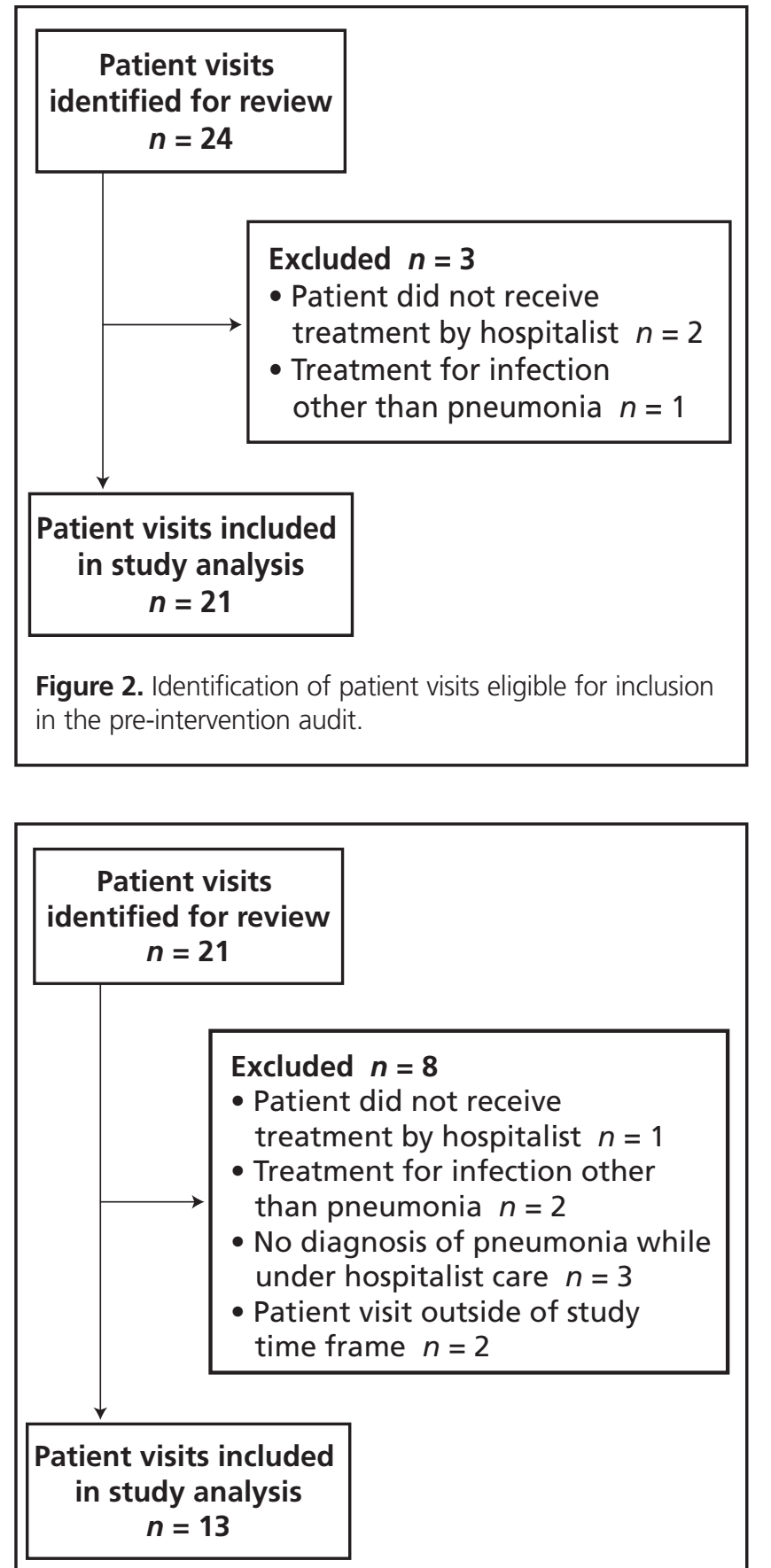

Figure 3. Identification of patient visits eligible for inclusion in the post-intervention audit.

\section{Adherence to Best Practice}

The results from the pre- and post-intervention audits were compared with identified best practice to determine the proportion of orders in adherence (Figure 1). The adherence rates were $10 \%(2 / 21)$ at baseline and $38 \%(5 / 13)$ in the post-intervention audit, a statistically significant 4 -fold increase (Table 4). 


\section{Table 2. American Thoracic Society/Infectious Diseases Society of America Risk Factors for Multidrug-Resistant Pathogens ${ }^{3}$}

\begin{tabular}{l}
\hline Antimicrobial therapy in preceding 90 days \\
\hline Current hospital stay of 5 days or more \\
\hline High frequency of antibiotic resistance in community (or in specific hospital unit)* \\
\hline Risk factors for health care-associated pneumonia: \\
- Admission to hospital for 2 days or more in preceding 90 days \\
- Residence in a nursing home or extended care facility \\
- Home infusion therapy (including antibiotics) \\
- Hong-term dialysis within 30 days \\
- Family member with multidrug-resistant pathogen* \\
Immunosuppressive disease and/or therapy \\
*These factors were excluded from consideration in the AFFECT study.
\end{tabular}

Table 3. Positive Respiratory Isolates for Inpatients*

\begin{tabular}{lc} 
Organism & $\begin{array}{r}\text { No. (\%) of Respiratory } \\
\text { Isolates }(\boldsymbol{n}=\mathbf{6 2 1})\end{array}$ \\
\hline Streptococcus pneumoniae & $104(16.7)$ \\
Haemophilus spp. & $95(15.3)$ \\
Methicillin-susceptible & $84(13.5)$ \\
$\quad$ Staphylococcus aureus & \\
Pseudomonas aeruginosa & $54(8.7)$ \\
Moraxella catarrhalis & $46(7.4)$ \\
Methicillin-resistant & $39(6.3)$ \\
Staphylococcus aureus &
\end{tabular}

*Based on local antibiogram 2010/2011.

Major changes from the pre-intervention audit to the post-intervention audit were increases in the prescribing of amoxicillin-clavulanate and azithromycin and reductions in use of levofloxacin and moxifloxacin, changes that are consistent with the treatment algorithm recommendations (Table 5).

There were no significant changes in the duration of IV, oral, or total treatment from the pre-intervention to the postintervention audit, except for oral therapy in HCAP patients, which significantly decreased (Table 6). This finding was in direct contrast to the study objective of reducing the duration of IV therapy. There was, however, a nonsignificant trend to reduced duration of total therapy in the post-intervention group.

In the pre-intervention audit only 2 patients had a positive blood or respiratory culture, and the antibiotic was appropriately de-escalated to a narrower-spectrum agent on the basis of culture and sensitivity results. In the post-intervention audit, one patient had a positive respiratory culture, which was also appropriately de-escalated.

PSI and CURB-65 scores were not documented by any of the physicians in either phase of the study; however, the primary investigator was able to calculate the scores for all patients. Although these scores have not been validated for use in patients with HCAP and HAP, they were calculated for all patients in the AFFECT study in an attempt to measure disease severity in each group. The mean PSI and CURB-65 scores did not differ significantly between the pre-intervention and postintervention groups (Table 7). According to the PSI score, 33\% and $23 \%$ of patients in the pre- and post-intervention groups, respectively, qualified for outpatient management (Table 8). In both the pre- and the post-intervention groups, the CURB-65 scores suggested that a greater proportion of patients qualified for outpatient treatment, $52 \%$ and $31 \%$, respectively (Table 8 ). The difference in site-of-care recommendations between the PSI and CURB-65 scores was influenced by the advanced age of the study population (given that age influences the PSI score more significantly). ${ }^{18}$ The patients included in the study had a wide range of comorbid conditions that were not captured by either the PSI or CURB-65 scores but that likely influenced the severity of illness.

\section{Post-Intervention Feedback}

The primary investigator shared the post-intervention audit results with the hospitalists at their monthly meeting on May 30, 2013. Feedback on the post-intervention data was provided in the same concealed and individualized manner as during the initial presentation.

\section{DISCUSSION}

The following were the primary reasons for non-adherence to the pneumonia treatment algorithms by hospitalists: using fluoroquinolone or a second-generation cephalosporin, not prescribing treatment for MDR organisms for patients with a risk factor, treating patients with HCAP the same as those with CAP, and prescribing ciprofloxacin instead of tobramycin in patients with estimated creatinine clearance above $50 \mathrm{~mL} / \mathrm{min}$. In the pre-intervention audit, fluoroquinolone monotherapy was prescribed for the majority of patients, as recommended in the IDSA/ATS guidelines ${ }^{2,3}$; however, use of fluoroquinolone was not a recommendation in the local treatment algorithms. Low adherence in the pre-intervention audit can also be explained by the fact that antibiotic choices were likely based on past practice and published guidelines, not local treatment algorithms. 
Table 4. Adherence to Best-Practice Antibiotic Regimens

\begin{tabular}{|c|c|c|c|}
\hline \multirow[b]{2}{*}{ Type of Pneumonia } & \multicolumn{2}{|c|}{ No. (\%) of Patients* } & \multirow[b]{2}{*}{$p$ Value } \\
\hline & Pre-intervention & Post-intervention & \\
\hline Health care-associated & $1 / 14 \quad(7)$ & $1 / 6(17)$ & 0.52 \\
\hline Hospital-acquired & $0 / 4$ & $0 / 2 \quad(0)$ & NA \\
\hline Community-acquired & $1 / 3 \quad(33)$ & $4 / 5 \quad(80)$ & 0.19 \\
\hline Total & $2 / 21 \quad(10)$ & $5 / 13 \quad(38)$ & 0.043 \\
\hline
\end{tabular}

*Percentages are calculated on the basis of the number of cases within each type.

Table 5. Antibiotic Utilization

No. (\%) of Patients

\begin{tabular}{|c|c|c|c|}
\hline Antibiotic & $\begin{array}{c}\text { Pre-intervention } \\
(n=21)\end{array}$ & $\begin{array}{l}\text { Post-intervention } \\
(n=13)\end{array}$ & $p$ Value \\
\hline Cefuroxime & $7(33)$ & $3(23)$ & 0.52 \\
\hline Levofloxacin & $7(33)$ & 0 & 0.029 \\
\hline Moxifloxacin & 7 (33) & 1 (8) & 0.09 \\
\hline Ceftriaxone & $5(24)$ & $3(23)$ & 0.96 \\
\hline Piperacillin-tazobactam & $4(19)$ & $3(23)$ & 0.78 \\
\hline Azithromycin & $3(14)$ & $7(54)$ & 0.014 \\
\hline Ciprofloxacin & $3(14)$ & $2(15)$ & 0.93 \\
\hline Vancomycin & $3(14)$ & $1(8)$ & 0.56 \\
\hline Ceftazidime & $2(10)$ & $1 \quad(8)$ & 0.86 \\
\hline Metronidazole & $1 \quad(5)$ & 0 & 0.42 \\
\hline Trimethoprim-sulfamethoxazole & $1 \quad(5)$ & 0 & 0.42 \\
\hline Amoxicillin-clavulanate & 0 & $4(31)$ & 0.015 \\
\hline Gentamicin & 0 & 0 & NA \\
\hline Tobramycin & 0 & 0 & NA \\
\hline
\end{tabular}

NA = not applicable.

Table 6. Duration of Therapy

\begin{tabular}{|c|c|c|c|}
\hline \multirow[b]{2}{*}{$\begin{array}{l}\text { Type of Pneumonia and } \\
\text { Type of Therapy }\end{array}$} & \multicolumn{2}{|c|}{ Mean Duration \pm SD (days) } & \multirow[b]{2}{*}{$p$ Value } \\
\hline & $\begin{array}{l}\text { Pre-intervention } \\
\quad(n=21)\end{array}$ & $\begin{array}{l}\text { Post-intervention } \\
\quad(n=13)\end{array}$ & \\
\hline \multicolumn{4}{|l|}{ All types of pneumonia } \\
\hline Overall & $10.8 \pm 4.2$ & $9.1 \pm 3.8$ & 0.23 \\
\hline IV & $4.7 \pm 5.5$ & $5.0 \pm 4.7$ & 0.88 \\
\hline Oral & $6.3 \pm 4.1$ & $4.5 \pm 4.4$ & 0.24 \\
\hline \multicolumn{4}{|c|}{ Health care-associated pneumonia } \\
\hline Overall & $10.4 \pm 4.0$ & $9.0 \pm 5.1$ & 0.53 \\
\hline IV & $2.8 \pm 3.7$ & $6.5 \pm 5.2$ & 0.08 \\
\hline Oral & $7.9 \pm 3.2$ & $3.5 \pm 3.2$ & 0.012 \\
\hline \multicolumn{4}{|c|}{ Hospital-acquired pneumonia } \\
\hline Overall & $12.8 \pm 6.2$ & $8.0 \pm 1.4$ & 0.37 \\
\hline IV & $10.5 \pm 7.9$ & $7.0 \pm 0.0$ & 0.58 \\
\hline Oral & $2.3 \pm 3.2$ & $1.0 \pm 1.4$ & 0.64 \\
\hline \multicolumn{4}{|c|}{ Community-acquired pneumonia } \\
\hline Overall & $10.3 \pm 2.1$ & $9.6 \pm 3.2$ & 0.74 \\
\hline IV & $6.0 \pm 4.6$ & $2.4 \pm 4.3$ & 0.31 \\
\hline Oral & $4.3 \pm 5.1$ & $7.2 \pm 5.2$ & 0.48 \\
\hline
\end{tabular}

The hospitalists identified 2 additional reasons for nonadherence: the paper copy of the algorithm was inconvenient, and antibiotic therapy was often started in the emergency department, before the patient was seen by a hospitalist. If a patient had received only one dose before the hospitalist assumed care, the hospitalists generally felt comfortable changing therapy to adhere to the algorithm; however, if more than one dose had been administered, they felt less comfortable 
changing the therapy, especially if a therapeutic response had already occurred. It was suggested that a similar educational strategy be conducted with emergency department physicians, to promote consistent use of the algorithms. It was also suggested that transformation of the algorithms into a format compatible with mobile devices would facilitate increased use.

At the end of the post-intervention meeting, the hospitalists expressed interest in continued use of the algorithms. One of the hospitalists stated, "I like the algorithms. They slow me down in my thinking." Another said, "They are not algorithms that you are going to remember after using a few times. You have to reflect on the choices and then apply them to practice." The hospitalists also indicated that no situation arose in which they consciously decided not to use the algorithms.

The effectiveness of restrictive interventions on antibiotic prescribing has been shown to decrease with time; however, combining restrictive interventions with additional persuasive interventions, such as audit and feedback, may promote the longevity of effect. ${ }^{27}$ To promote the sustainability of the AFFECT study, the possibility of repeat audits of hospitalists' prescribing (either by the physicians themselves or by medical residents) being completed every 6 to 12 months was discussed. It was further suggested that a prospective audit could be developed using a simplified process and audit form, and that involving physicians in auditing their own practice could potentially have a greater and more sustainable impact.

\section{Limitations}

This study had several limitations. The data collection period was short, resulting in a small sample size, which made detection of a statistically significaunt difference difficult, as well as reducing the external generalizability of the results. The
Table 7. Mean PSI and CURB-65 Scores

\begin{tabular}{lccc} 
& \multicolumn{2}{c}{ Mean \pm SD } & \\
\cline { 2 - 3 } & Pre-intervention & Post-intervention & $p$ Value \\
\hline PSI* & $99.7 \pm 33.8$ & $112.2 \pm 25.9$ & 0.26 \\
\hline CURB-65† & $1.6 \pm 1.5$ & $1.8 \pm 1.0$ & 0.75 \\
\hline
\end{tabular}

PSI = Pneumonia Severity Index; CURB-65 = severity score based on confusion, urea, respiratory rate, blood pressure, and age; SD = standard deviation

* Maximum possible score for PSI varies with age, with the highest score class having values $>130$

†Maximum possible score for CURB-65 = 5 .

short study duration also prevented participation by all hospitalists, as not all of the hospitalists were scheduled to work during the study period.

Because of the short duration of data collection, outcomes such as 30-day mortality and hospital readmission were not considered.

More generally, the hospitalists at this institution are a small group of physicians with a keen interest in practice improvement. The study methods used here may not be suitable for other, more diverse physician groups.

\section{CONCLUSIONS}

An audit and feedback-based intervention focusing on hospitalists' antibiotic prescribing for pneumonia increased adherence to local best practice and resulted in a nonsignificant trend toward reduced duration of treatment. Future audit and feedback-based interventions focusing on other physician groups and different infections or disease states could be undertaken using these study methods.

\section{Table 8. Percentage of Patients in PSI and CURB-65 Risk Classes before and after Intervention}

No. (\%) of Patients

\begin{tabular}{lccc} 
Risk Class & Recommended Site of Care & $\begin{array}{c}\text { Pre-intervention } \\
(\boldsymbol{n}=\mathbf{2 1})\end{array}$ & $\begin{array}{c}\text { Post-intervention } \\
(\boldsymbol{n}=\mathbf{1 3})\end{array}$ \\
\hline PSI & Outpatient & $0(0)$ & $0(0)$ \\
I II & Outpatient & $4(19)$ & $0(0)$ \\
III & Outpatient & $3(14)$ & $3(23)$ \\
IV & Inpatient & $9(43)$ & $6(46)$ \\
V & Inpatient & $5(24)$ & $4(31)$ \\
\hline CURB-65 & Outpatient & $5(24)$ & 1 \\
0 & Outpatient & $6(29)$ & $3(23)$ \\
1 & Short-stay inpatient or & $5(24)$ & $7(54)$ \\
2 & supervised outpatient & & \\
& Inpatient & $2(10)$ & 1 \\
3 & Inpatient & $0(0)$ & 1 \\
4 & Inpatient ICU & $2(10)$ & $0(0)$ \\
5 & S & $(8)$
\end{tabular}

PSI = Pneumonia Severity Index; CURB-65 = severity score based on confusion, urea, respiratory rate, blood pressure, and age; ICU = intensive care unit. 


\section{References}

1. Leading causes of death in Canada-2009. Catalogue No. 84-215-XWE. Ottawa (ON): Statistics Canada; 2012 [cited 2012 Aug 18]. Available from: www.statcan.gc.ca/pub/84-215-x/2012001/tbl/T001-eng.pdf

2. Mandell LA, Wunderink RG, Anzueto A, Bartlett JG, Campbell GD, Dean NC, et al. Infectious Diseases Society of America/American Thoracic Society consensus guidelines on the management of community-acquired pneumonia in adults. Clin Infect Dis. 2007;44 Suppl 2:S27-72.

3. American Thoracic Society and Infectious Diseases Society of America. Guidelines for the management of adults with hospital-acquired, ventilatorassociated, and healthcare-associated pneumonia. Am J Respir Crit Care Med. 2005;171(4):388-416.

4. Rotstein C, Evans G, Born A, Grossman R, Light B, Magder S, et al. Clinical practice guidelines for hospital-acquired pneumonia and ventilator-associated pneumonia in adults. Can J Infect Dis Med Microbiol. 2008;19(1):19-53.

5. Jarvis W. Selected aspects of the socioeconomic impact of nosocomial infections: morbidity, mortality, cost, and prevention. Infect Control Hosp Epidemiol. 1996;17(8):552-7.

6. Schaffer K, Fitzgerald S, Gonzalez-Sanchez Z, Fenelon L. Do educational interventions improve management of patients with community-acquired pneumonia? J Healthc Qual. 2006;28(6):7-12.

7. Seppala H, Klaukka T, Vuopio-Varkila J, Muotiala A, Helenius H, Lager K, et al. The effect of changes in the consumption of macrolide antibiotics on erythromycin resistance in group A streptococci in Finland. Finnish Study Group for Antimicrobial Resistance. N Engl J Med. 1997;337(7):441-6.

8. Gonzales R, Bartlett JG, Besser RE, Cooper RJ, Hickner JM, Hoffman JR, et al. Principles of appropriate antibiotic use for treatment of acute respiratory tract infections in adults: background, specific aims, and methods. Ann Intern Med. 2001;134(6):479-86.

9. Battleman DS, Callahan M, Thaler HT. Rapid antibiotic delivery and appropriate antibiotic selection reduce length of hospital stay of patients with community-acquired pneumonia: link between quality of care and resource utilization. Arch Intern Med. 2002;162(6):682-8.

10. Torres A, Ferrer M, Badia JR. Treatment guidelines and outcomes of hospitalacquired and ventilator-associated pneumonia. Clin Infect Dis. 2010;51(1): S48-53.

11. Kollef MH, Ward S. The influence of mini-BAL cultures on patient outcomes: implications for the antibiotic management of ventilator-associated pneumonia. Chest. 1998;113(2):412-20.

12. Luna CM, Vujacich P, Niederman MS, Vay C, Gherardi C, Matera J, et al. Impact of BAL data on the therapy and outcome of ventilator-associated pneumonia. Chest. 1997;111(3):676-85.

13. Alvarez-Lerma F. Modification of empiric antibiotic treatment in patients with pneumonia acquired in the intensive care unit. ICU-Acquired Pneumonia Study Group. Intensive Care Med. 1996;22(5):387-94.

14. File TM, Solomkin JS, Cosgrove SE. Strategies for improving antimicrobial use and the role of antimicrobial stewardship programs. Clin Infect Dis. 2012;53 Suppl 1:S15-22.

15. Infection prevention and control guideline for the prevention of healthcareassociated pneumonia. Ottawa (ON): Public Health Agency of Canada; 2012 [cited 2012 Aug 19]. Available from: www.phac-aspc.gc.ca/nois-sinp/guide/ pneu-gl-ld/part-b-eng.php

16. Mandell LA, Wunderink RG, Anzueto A, Bartlett JG, Campbell GD, Dean NC, et al. Guidelines pocketcard: Community-acquired pneumonia in adults. IDSA Guidelines Apps. Arlington (VA): Infectious Diseases Society of America; 2007 [cited 2012 Aug 19]. Available from: http://eguideline. guidelinecentral.com/i/53989 (payment required to access the app).

17. Ananda-Rajah MR, Charles PG, Melvani S, Burrell LL, Johnson PD, Grayson ML. Comparing the pneumonia severity index with CURB-65 in patients admitted with community acquired pneumonia. Scand J Infect Dis. 2008; 40(4):293-300.

18. Fine MJ, Auble TE, Yealy DM, Hanusa BH, Weissfeld LA, Singer DE, et al. A prediction rule to identify low-risk patients with community-acquired pneumonia. N Engl J Med. 1997;336(4):243-50.

19. Lim W, van der Eerden MM, Laing R, Boersma W, Karalus N, Town G, et al. Defining community acquired pneumonia severity on presentation to hospital: an international derivation and validation study. Thorax. 2003; 58(5):377-82.
20. Asadi L, Eurich DT, Gamble JM, Minhas-Sandhu JK, Marrie TJ, Majumdar SR. Guideline adherence and macrolides reduced mortality in outpatients with pneumonia. Respir Med. 2012;106(3):451-8.

21. Mandell LA, Marrie TJ, Grossman RF, Chow AW, Hyland RH. Canadian guidelines for the initial management of community-acquired pneumonia: an evidence-based update by the Canadian Infectious Diseases Society and the Canadian Thoracic Society. Canadian Community-Acquired Pneumonia Working Group. Clin Infect Dis. 2000;31(2):383-421.

22. Liu C, Bayer A, Cosgrove SE, Daum RS, Fridkin SK, Gorwitz RJ, et al. Clinical practice guidelines by the Infectious Diseases Society of America for the treatment of methicillin-resistant Staphylococcus aureus infections in adults and children. Clin Infect Dis. 2011;52(3):18-55.

23. Masterton RG, Galloway A, French G, Street M, Armstrong J, Brown E, et al. Guidelines for the management of hospital-acquired pneumonia in the UK: report of the Working Party on Hospital-Acquired Pneumonia of the British Society for Antimicrobial Chemotherapy. J Antimicrob Chemother. 2008;62(1):5-34.

24. Levy M, Le Jeune I, Woodhead MA, Macfarlane JT, Lim WS; British Thoracic Society Community Acquired Pneumonia in Adults Guideline Group. Primary care summary of the British Thoracic Society guidelines for the management of community acquired pneumonia in adults: 2009 update. Prim Care Respir J. 2010:19(1):21-7.

25. Dellit TH, Owens RC, McGowan JE Jr, Gerding DN, Weinstein RA, Burke $J P$, et al. Infectious Diseases Society of America and the Society for Healthcare Epidemiology of America guidelines for developing an institutional program to enhance antimicrobial stewardship. Clin Infect Dis. 2007;44(2):159-77.

26. Boucher HW, Talbot GH, Bradley JS, Edwards JE, Gilbert D, Rice LB, et al. Bad bugs, no drugs: no ESKAPE! An update from the Infectious Diseases Society of America. Clin Infect Dis. 2009;48(1):1-12.

27. Davey P, Brown E, Charani E, Fenelon L, Gould IM, Holmes A, et al. Interventions to improve antibiotic prescribing practices for hospital inpatients. Cochrane Database Syst Rev. 2013;4:CD003543.

28. Ivers N, Jamtvedt G, Flottorp S, Young JM, Odgaard-Jensen J, French SD, et al. Audit and feedback: effects on professional practice and healthcare outcomes. Cochrane Database Syst Rev. 2012;6:CD000259.

29. Flottorp SA, Jamtvedt G, Gibis B, McKee M. Using audit and feedback to health professionals to improve the quality and safety of health care. Policy Summary 3. prepared for Belgian EU Presidency Conference on Investing in Europe's health workforce of tomorrow: scope for innovation and collaboration. Geneva (Switzerland): World Health Organization and WHO on behalf of European Observatory on Health Systems and Policies; 2010.

30. Drew RH. Antimicrobial stewardship programs: how to start and steer a successful program. J Manag Care Pharm. 2009;15(2):S18-23.

31. Johannsson B, Beekmann SE, Srinivasan A, Hersh AL, Laxminarayan R, Polgreen PM. Improving antimicrobial stewardship: the evolution of programmatic strategies and barriers. Infect Control Hosp Epidemiol. 2011; 32(4):367-74.

32. Elligsen M, Walker SA, Simor A, Daneman N. Prospective audit and feedback of antimicrobial stewardship in critical care: program implementation, experience, and challenges. Can J Hosp Pharm. 2012;65(1):31-6.

33. Elligsen M, Walker SA, Pinto R, Simor A, Mubareka S, Rachlis A, et al. Audit and feedback to reduce broad-spectrum antibiotic use among intensive care unit patients: a controlled interrupted time series analysis. Infect Control Hosp Epidemiol. 2012;33(4):354-61.

34. CSHP 2015 goals and objectives. Ottawa (ON): Canadian Society of Hospital Pharmacists; 2011 [cited 2012 Sep 9]. Available from: www.cshp.cal $\mathrm{dms} / \mathrm{dmsView} / 2$ _CSHP-2015-Goals-and-Objectives-Feb-25\%2707-wAppdx-rev-May\%2708.pdf

35. Hospitalists: leading the way to more effective, higher quality health care. Philadelphia (PA): Society of Hospital Medicine; 2012 [cited 2012 Oct 10]. Available from: http://medicalreimbursementinc.com/utility-pages/resources/ hospitalists-leading-the-way-to-more-effective-higher-quality-he/

36. Peterson MC. A systematic review of outcomes and quality measures in adult patients cared for by hospitalists vs nonhospitalists. Mayo Clin Proc. 2009;84(3):248-54.

37. Quinn R. New mindset on antibiotics: de-escalation strategies could improve efficiency, cost of care. In: The eWire. Society of Hospital Medicine; 2012 Nov 1 [cited 2014 Jan. 16]. Available from: www.the-hospitalist.org/details/ article/1438795/New_Mindset_on_Antibiotics.html 
38. Kollef MH, Morrow LE, Baughman RP, Craven DE, McGowan JE Jr, Micek ST, et al. Health care-associated pneumonia (HCAP): a critical appraisal to improve identification, management, and outcomes-proceedings of the HCAP Summit. Clin Infect Dis. 2008;46 Suppl 4:S296-334.

39. Anand N, Kollef MH. The alphabet soup of pneumonia: CAP, HAP, HCAP, NHAP, and VAP. Semin Respir Crit Care Med. 2009;30(1):3-9.

40. Madaras-Kelly K, Remington R, Sloan K, Fan V. Guideline-based antibiotics and mortality in healthcare-associated pneumonia. J Gen Intern Med. 2012; 27(7):845-52.

41. Grenier C, Pépin J, Nault V, Howson J, Fournier X, Poirier MS, et al. Impact of guidelines-consistent therapy on outcome of patient with healthcareassociated and community-acquired pneumonia. $J$ Antimicrob Chemother. 2011;66(7):1617-24.

42. Wunderink RG. Healthcare-associated bacteremia: stirring the mud. Crit Care Med. 2006;34(10):2685-86.

43. Drinka PJ, Gauerke C, Voeks S, Miller J, Schultz S, Krause P, et al. Pneumonia in a nursing home. J Gen Intern Med. 1994;9(11):650-2.

44. Troy CJ, Peeling RW, Ellis AG, Hockin JC, Bennett DA, Murphy MR, et al. Chlamydia pneumoniae as a new source of infectious outbreaks in nursing homes. JAMA. 1997;277(15):1214-8. Erratum in: JAMA. 1997;278(2):118.

45. Orr PH, Peeling RW, Fast M, Brunka J, Duckworth H, Harding GK, et al. Serological study of response to selected pathogens causing respiratory tract infection in the institutionalized elderly. Clin Infect Dis. 1996;23(6):1240-5.

46. Kollef MH, Shorr A, Tabak YP, Gupta V, Liu LZ, Johannes RS. Epidemiology and outcomes of healthcare-associated pneumonia: results from a large US database of culture positive pneumonia. Chest. 2005;128(6):3854-62.

47. The bacterial challenge: time to react. A call to narrow the gap between multi-drug resistant bacteria in the $E U$ and the development of new antibacterial agents. European Centre for Disease Prevention and Control and European Medicines Agency joint technical report. Stockholm (Sweden): European Centre for Disease Prevention and Control; 2009 [cited 2013 May 26]. Available from: www.ema.europa.eu/docs/en_GB/document_library/Report/ 2009/11/WC500008770.pdf

48. Resistance map. In: Explore the data [website]. Washington (DC): Center for Disease Dynamics, Economics \& Policy; [cited 2013 May 26]. Available from: www.cddep.org/map

49. Lister PD, Wolter DJ, Hanson ND. Antibacterial-resistant Pseudomonas aeruginosa: clinical impact and complex regulation of chromosomally encoded resistance mechanisms. Clin Microbiol Rev. 2009;22(4):582-610.

50. Lexi-Drugs Online [database on Internet]. Hudson (OH): Lexi-Comp, Inc; (c) 1978-2013 [cited 2013 April 8]. Available from: http://online.lexi.com/. Registration required to access content.

51. Dynamed Online [database on Internet]. Ipswich (MA): EBSCO Publishing; 2013 [cited 2013 April 8]. Available from: https://dynamed.ebscohost.com. Registration required to access content.

52. Al-Rawahi GN, Schreader AG, Porter SD, Roscoe DL, Gustafson R, Bryce EA. Methicillin-resistant Staphylococcus aureus nasal carriage among injection drug users: six years later. J Clin Microbiol. 2008;46(2):477-9.

53. Bassetti S, Battegay M. Staphylococcus aureus infections in injection drug users: risk factors and prevention strategies. Infection. 2004;32(3):163-9.
54. Brown E, Nathwani D. Antibiotic cycling or rotation: a systematic review of the evidence of efficacy. J Antimicrob Chemother. 2005;55(1):6-9.

55. Davies J, Davies D. Origins and evolution of antibiotic resistance. Microbiol Mol Biol Rev. 2010;74(3):417-33.

Katelyn Halpape, BSP, ACPR, is a PharmD student in the Faculty of Pharmaceutical Sciences, University of British Columbia, Vancouver, British Columbia. She completed her pharmacy practice residency with the Regina Qu'Appelle Health Region, Regina, Saskatchewan, in 2012/2013.

Linda Sulz, BSP, PharmD, is with Regina Qu'Appelle Health Region, Regina, Saskatchewan.

Brenda Schuster, BSP, ACPR, PharmD, FCSHP, is with Regina Qu'Appelle Health Region, and the Department of Academic Family Medicine, University of Saskatchewan, Regina, Saskatchewan.

Ron Taylor, MD, CCFP(EM), is with Regina Qu'Appelle Health Region, Regina, Saskatchewan.

Competing interests: Linda Sulz is Chair of the Regina Qu'Appelle Health Region Antimicrobial Stewardship Program (formerly the Antimicrobial Utilization Committee). She has received reimbursement from Janssen and Gilead for expenses related to advisory board meetings; reimbursement from Janssen, Merck, and Sunovion for conference attendance; and honoraria from Pfizer, Sanofi, and Merck for a "Train the Trainer" webinar and for continuing education presentations. None declared by the other authors.

\section{Address correspondence to:}

Katelyn Halpape

Maple 05-027 Ponderosa Commons

2205 Lower Mall

Vancouver BC V6T1Z4

e-mail: katelynhalpape@gmail.com

\section{Acknowledgements}

We thank Ali Bell, statistical analyst and research scientist with the Department of Research and Health Information Services, Regina Qu'Appelle Health Region, for assistance with the statistical analyses; Dr. John Alport, Dr. Marty Heroux, Dr. Fouche Williams, Dr. Andrew Kielly, Dr. Kathy Ferguson, Dr. Abraham Vermeulen, Dr. Kish Lyster, and Dr. Wilna Wildenboer, hospitalists in the Department of Family Medicine, Regina Qu'Appelle Health Region, for their participation in the study; and staff of Health Information Management Services, Regina Qu'Appelle Health Region, for assistance with data management. 